\title{
Physical Activity is Associated with Less Analgesic Use in Women Reporting Headache-A Cross-Sectional Study of the German Migraine and Headache Society (DMKG)
}

\author{
Britta Müller · Charly Gaul • Änne Glass · Olaf Reis • Tim P. Jürgens • \\ Peter Kropp · Ruth Ruscheweyh · Andreas Straube · Elmar Brähler • \\ Stefanie Förderreuther · Thomas Dresler
}

Received: November 8, 2021 / Accepted: February 2, 2022 / Published online: February 25, 2022

(C) The Author(s) 2022

\section{ABSTRACT}

Introduction: The aim of this analysis is to determine whether regular physical activity is associated with less analgesic use in men and women suffering from headache disorders based on population-based cross-sectional data.

Methods: We used data from a random general population sample in Germany that comprised 2477 participants aged $\geq 14$ years. A standardized questionnaire addressing headache and

B. Müller $(\varangle) \cdot$ P. Kropp

Institute of Medical Psychology and Medical

Sociology, Rostock University Medical Center, Gehlsheimer Str. 20, 18147 Rostock, Germany e-mail: britta.mueller@med.uni-rostock.de

C. Gaul

Headache Center Frankfurt, Frankfurt, Germany

Ä. Glass

Institute for Biostatistics and Informatics in

Medicine and Ageing Research, Rostock University

Medical Center, Rostock, Germany

O. Reis

Clinic for Child and Adolescent Psychiatry, Rostock

University Medical Center, Rostock, Germany

T. P. Jürgens

Department of Neurology, Rostock University

Medical Center, Rostock, Germany

R. Ruscheweyh · A. Straube $\cdot$ S. Förderreuther Department of Neurology, Ludwig Maximilian University of Munich, Munich, Germany headache treatment was filled in during the face-to-face survey.

Results: Thirty-nine percent of the participants reported headache. Of these, $37.5 \%$ of men and $33.6 \%$ of women were physically active. Of the participants with headache, $43.3 \%$ reported taking analgesics on $<2$ days a month, $40.7 \%$ on $2-5$ days a month, $10.1 \%$ on $6-10$ days a month, and $5.9 \%$ on $>10$ days a month. Frequent headache, severe impact of headache on daily life, and depressive symptoms were associated with higher analgesic use in both men

\section{E. Brähler}

Integrated Research and Treatment Center (IFB)

Adiposity Diseases, Behavioral Medicine,

Psychosomatic Medicine and Psychotherapy, University of Leipzig Medical Center, Leipzig, Germany

\section{E. Brähler}

Department of Psychosomatic Medicine and Psychotherapy, University Medical Center of the Johannes Gutenberg-University, Mainz, Germany

\section{T. Dresler}

Department of Psychiatry \& Psychotherapy, Tübingen Center for Mental Health, University Hospital Tübingen, Tübingen, Germany

\section{T. Dresler}

LEAD Graduate School \& Research Network, University of Tübingen, Tübingen, Germany 
and women. For women, physical inactivity was associated with the frequency of analgesic use adjusted for sociodemographic and headacherelated variables. For men, results did not suggest any association between physical inactivity and frequency of analgesic use.

Conclusions: There are both sex-unspecific and sex-specific factors associated with analgesic use among men and women with headache. In women with increased analgesic use, promoting physical activity may reduce analgesic use. For men, education about the therapeutic effects of physical activity for headaches is an important resource.

Keywords: Headache; Analgesic use; Physical activity

\section{Key Summary Points}

\section{Why carry out this study?}

For migraine and tension-type headaches, there is evidence that physical activity can alleviate headache suffering.

Substantially fewer studies have investigated effects of physical activity on the use of acute headache medication.

The study tested whether regular physical exercise is associated with less analgesic use in men and women suffering from headache disorders based on populationbased cross-sectional data.

\section{What was learned from the study?}

Physical inactivity was associated with the frequency of analgesic use in women, but not in men.

The results suggest the prophylactic potential for exercise to positively influence patients' headache. Especially women with high analgesic use should be educated about the solid evidence of physical activity for prophylactic treatment of headache and, in addition, about the risk of medication overuse headache.

\section{INTRODUCTION}

The prophylactic effects of exercise on primary headache have been studied during recent years, focusing on its effects on headache frequency, attack duration, and pain intensity [1].

For migraine, there is moderate evidence that aerobic exercise reduces the number of migraine days. Regarding the effect on attack duration and pain intensity, recent studies are not conclusive $[1,2]$. In experimental studies, exercise has also been demonstrated to be a potential trigger for migraine attacks [3], and the International Classification of Headache Disorders, 3rd edition (ICHD-3) under 4.2 codes a special idiopathic headache form, primary exercise headache, which has a high comorbidity with migraine [4].

For tension-type headache (TTH), findings rather suggest positive effects of strength training on headache days as opposed to aerobic workouts [2]. Regarding pain intensity and duration of TTH, findings are inconsistent $[2,5]$. However, as the majority of findings support the concept, regular physical exercise is recommended for the prevention of migraine and TTH in national and international guidelines [6-8].

Substantially fewer studies have investigated effects of exercise on the use of acute headache medication. For migraine and TTH, the mainstays in the acute treatment are analgesics (e.g., paracetamol) and non-steroidal anti-inflammatory drugs (NSAIDs) (e.g., acetylsalicylic acid, ibuprofen). For migraine, triptans are additionally recommended if attacks do not respond to the aforementioned substances [7]. To our knowledge, only the prospective study of Krøll \& Hammarlund [9], including individuals suffering from migraine, coexisting TTH and neck pain, investigated whether physical activity affects acute medication use. They did not report any effect $[9,10]$. Interestingly, however, studies that did not examine acute medication use directly, but rather medication overuse and medication overuse headache $(\mathrm{MOH})$, suggest associations with physical activity. Based on a prospective study, physical inactivity was reported to double the risk of $\mathrm{MOH}$ after 
11 years [11]. In a cross-sectional study investigating potential influencing factors for chronic migraine, Viana \& Bottiroli [12] found that physical inactivity was a factor more associated with having chronic migraine and medication overuse than with having episodic migraine. A Spanish population-based study on self-medication in the general population suggests a negative association between physical activity and self-medication [13]. As this study generally asked for medication consumption not prescribed by a doctor, which also includes various medications for fever, cough, or gastrointestinal problems, its implication for headache patients is largely inconclusive.

In sum, it remains unclear whether physical activity reduces not only headache but also the use of acute medication. Headache disorders, however, especially migraine and $\mathrm{MOH}$, are associated with high acute treatment costs [14].

The aim of this analysis is to determine whether regular physical exercise is associated with analgesic use in men and women suffering from headache disorders based on populationbased cross-sectional data. We hypothesize that headache sufferers consume less acute medication if they are physically more active.

\section{METHODS}

\section{Participants}

The analysis is based on data from a random general population sample in Germany with participants aged 14-94 years. A cross-sectional questionnaire survey was performed by face-toface interviews conducted by an independent demographic consulting company (USUMA, Berlin, Germany). Of the total 4838 persons selected, 2510 were included (52\%). Details on the sampling procedure were described previously [22]. An adjustment factor was calculated based on the German population structure regarding age, sex, household size, and population, by federal state. Using the adjustment factor, a weighted random sample was created, the structure of which corresponds to that of the German population. Thirty-two participants were excluded due to missing answers [22]. Data collection took place from September to November 2016. All participants gave their written informed consent. The Ethics Committee of the Faculty of Medicine, University of Leipzig reviewed and approved the study (297/16-ek). Furthermore, the ethics guidelines of the International Code of Marketing and Social Research Practice of the European Society for Opinion and Marketing Research were observed.

\section{Questionnaire}

A standardized questionnaire on headache and headache treatment was used. It started with the screening question "Did you have a headache during the last 6 months?".

\section{Dependent Variable: Analgesic Use}

Acute treatment of headache was assessed with the question: "How many days a month do you use analgesics on average?" For statistical analysis, the metric variable was transformed to an ordinal variable, (1) $<2$ days a month; (2) 2-5 days a month; (3) 6-10 days a month; (4) $>10$ days a month.

\section{Independent Variable: Physical Activity}

Physical activity was surveyed with the dichotomous question: "Do you exercise regularly (i.e., on average at least 2-3 times a week for $30 \mathrm{~min}$ or longer)?" (Yes/No). Participants were categorized as physically active if they answered "yes" and as physically inactive otherwise.

\section{Covariates}

Sociodemographic variables encompassed sex, age in years, and marital status (married/cohabiting, separated, never married, divorced, widowed).

Headache frequency was assessed using a five-point ordinal scale: $(1)<1$ day a month; (2) 1-3 days a month; (3) 4-14 days a month; (4) $>14$ days a month but not daily; (5) daily. For statistical analysis, the five categories were merged into three categories: $<4$ days a month, 4-14 days a month, $>14$ days a month. 
The impact of headache on daily life was measured using the German version of the Headache Impact Test (HIT-6) [15]. The total score ranges from 36 to 78 . Higher scores indicate a greater impact of headache on the ability to function on the job, at school, at home, and in social situations. The HIT- 6 provides a grading indicating four levels of headache impact: no or little impact $(<50)$, some impact $(50-55)$, substantial impact (56-59), and severe impact ( $\geq 60$ ).

Additionally, headache duration in years was considered. Migraine was assessed through participants' self-reported migraine diagnosis made by a physician. Self-report data on body weight and height were collected to calculate the body mass index (BMI) $\left(\mathrm{kg} / \mathrm{m}^{2}\right)$. Obesity was defined as a $\mathrm{BMI}>30 \mathrm{~kg} / \mathrm{m}^{2}[16]$.

Depressive symptoms were measured with the subscale of the Patient Health Questionnaire (PHQ-4) that encompasses two items and has sum scores ranging from 0 to 6 . Scores $\geq 3$ indicate the presence of significant depressive symptoms $[17,18]$.

\section{Statistical Analysis}

Two-tailed tests (Fisher's exact test, Welch's $t$ test, $t$ test, Pearson's $\chi^{2}$ test) were used to test for differences between physically active and inactive participants reporting headache. Multiple comparisons were adjusted using the Holm-Bonferroni procedure [19, 20]. Recommendations by Agresti and Kateri [21] were applied for the interpretation of effects of categorical variables. These authors suggest the use of adjusted standardized residuals (standardized Pearson residual) to evaluate deviations between observed and expected frequencies. An adjusted residual exceeding 2 or 3 in absolute value indicates a rather unlikely deviation which can be interpreted as significant. In the present analysis, deviations exceeding a value of 2 were considered significant.

Non-parametric one-way and two-way ANOVAs were calculated to test the effects of sex and physical activity on frequency of analgesic use.
To test the effect of physical activity on frequency of analgesic use, stratified for women and men, ordinal logistic regression analyses were conducted. The ordinal logistic regressions were sequentially adjusted for the set of sociodemographic variables (Model 2), headache-related variables (Model 3) and other health-related variables (Model 4). Prerequisites of ordinal logistic regressions, namely, no multicollinearity, and proportional odds were tested. No multicollinearity was observed for the independent variables of the subsample of women and the subsample of men. The proportional odds assumption was given for both subsamples and for all models. The analytical details are outlined in the results section.

A $p$ value $<0.05$ was considered statistically significant. Statistical analyses were performed using IBM SPSS Statistics 27 (SPSS Inc., Chicago, IL, USA).

\section{RESULTS}

\section{Sociodemographic Characteristics}

Thirty-nine percent, 95\% CI [37.1\%, 40.9\%] of the study sample reported headache during the previous 6 months. Women reported headache $(47.8 \%)$ more often than men $(29.8 \%), \chi^{2}(1)$ $=85.6, p<0.001, \varphi=0.19$. The sociodemographic characteristics of the total sample $(N=2477)$ according age, marital status, education, living with partner, and living environment have already been presented in a previously published open access article [22]. Of the participants without headache, $42.6 \%$ were physically active, while the proportion of physically active persons among those with headache was $35.1 \%, \chi^{2}(1)=13.55, p<0.001$, $\varphi=0.08$. While persons without headache showed a significant sex difference in physical activity (men 47.4\%, women 36.5\%), $\chi^{2}(1)=17.44, \quad p<0.001, \quad \varphi=0.11, \quad$ physical activity did not differ for sex in participants with headache (men $37.5 \%$, women $33.6 \%$ ), $\chi^{2}(1)=1.47, p=0.225, \varphi=0.04$. Of the participants with headache, $87.4 \%$ lived in an urban environment. Physical activity did not differ for 
living environment, $\chi^{2}(1)=0.04, \quad p=0.835$, $\varphi=0.07$.

Descriptive statistics of the participants with headache regarding physical activity and sex are shown in Table 1 . There was a significant age difference between physically active and physically inactive participants. Physically active women were 5.8 years younger than inactive ones, 95\% CI $[2.78,8.71], \quad t(596)=3.81$, $p=0.009$, physically active men were 11.5 years younger than inactive ones, 95\% CI [7.90, 15.07], $t(351)=6.30, p=0.009$. Widowed men were under-represented (adjusted residual: - 2.8) and never married men were over-represented (adjusted residual: 3.9 ) among physically active men, $\chi^{2}(4)=20.25, p=0.009$. In men, there was a significant inverse association between physical activity and obesity, $\chi^{2}(1)=11.80, p=0.009$, indicating that lower physical activity was associated with more obesity.

\section{Frequency of Analgesic Use Depending on Sex and Physical Activity}

Of participants with headache, $43.3 \%$ reported taking analgesics on $<2$ days a month, $40.7 \%$ on 2-5 days a month, $10.1 \%$ on $6-10$ days a month and $5.9 \%$ on $>10$ days a month. A nonparametric two-way ANOVA was employed to assess the effects of sex and physical activity on the frequency of analgesic use. The frequency of analgesic use differed significantly for sex, $\chi^{2}(1,993)=30.57, p<0.001$ and physical activity $\chi^{2}(1,993)=12.11, p<0.001$. There was a statistically significant interaction between sex and physical activity on the frequency of analgesic use, $\chi^{2}(1,993)=6.16, p=0.025$. Mean frequency of analgesic use (days a month) was lower among men $(M=2.71, S D=4.50)$ than in women $(M=4.25, S D=6.10)$. Physically active participants took analgesics on fewer days $(M=2.99, S D=5.01)$ than physically inactive participants $(M=4.05, S D=5.88)$. Subordinate ANOVAs revealed that this effect was only driven by women, as analgesic use differed significantly between physically active and inactive women, $\chi^{2}(1,631)=23.57, p<0.001$, but not in men, $\left.\chi^{2}(3,361)=0.46, p=0.500\right)$. Physically active women took analgesics on fewer days $(M=3.17, S D=5.34)$ than physically inactive women $(M=4.79, S D=6.38)$. Physically active and inactive men had the same mean number of analgesic use days $(M=2.71, S D=4.44$ resp. $M=2.71, S D=4.54)$. The interaction between sex and physical activity on the frequency of analgesic use, based on the ordinal item, is shown in Fig. 1.

In addition, $\chi^{2}$ tests were performed between physical activity and analgesic use for the headache groups "persons with migraine" and "persons with headache, other than migraine", separately for women and men. Results for women showed significant associations between physical activity and analgesic use in the group of women with migraine, $\chi^{2}(1)=8.59, p=0.035$, and in the group of women with headache, other than migraine, $\chi^{2}(1)=13.41, p=0.004$. In men, no association was found between physical activity and analgesic use, either in the migraine group, $\chi^{2}(1)=1.60, p=0.661$ or in the group of those with headache, other than migraine, $\chi^{2}(1)=1.53, p=0.676$.

\section{Frequency of Analgesic Use Depending on Physical Activity with Adjustment for Covariates}

Ordered logit models, separately for women and men, were estimated to investigate whether physical activity predicted the frequency of analgesic use $(<2$ days a month, $2-5$ days a month, 6-10 days a month, $>10$ days a month).

For women, results of the ordinal regression showed that physical inactivity was associated with the frequency of analgesic use, $O R=2.19$, $95 \%$ CI $[1.59,3.00]$, Wald $\chi^{2}(1)=23.36$, $p<0.001$ (Model 1). This association remained statistically significant when sociodemographic variables (Model 2), sociodemographic and headache-related variables (Model 3), and sociodemographic, headache-related and health variables were considered, $O R=1.84,95 \% C I$ $[1.29,2.64]$, Wald $\chi^{2}(1)=11.17, p=0.001$ (Model 4) (Table 2). 
Table 1 Descriptive statistics of participants reporting headache

\begin{tabular}{|c|c|c|c|c|c|c|c|}
\hline & \multirow{2}{*}{$\begin{array}{l}\text { All } \\
N=950\end{array}$} & \multicolumn{3}{|l|}{ Women } & \multicolumn{3}{|l|}{ Men } \\
\hline & & $\begin{array}{l}\text { Physical } \\
\text { activity } \\
N=201\end{array}$ & $\begin{array}{l}\text { Physical } \\
\text { inactivity } \\
N=397\end{array}$ & $\begin{array}{l}p \text { value } \\
(\text { adj. })^{4}\end{array}$ & $\begin{array}{l}\text { Physical } \\
\text { activity } \\
N=132\end{array}$ & $\begin{array}{l}\text { Physical } \\
\text { inactivity } \\
N=220\end{array}$ & $\begin{array}{l}p \text { value } \\
(\text { adj. })^{4}\end{array}$ \\
\hline \multicolumn{8}{|l|}{$\begin{array}{l}\text { Sociodemographic } \\
\text { variables }\end{array}$} \\
\hline Age, $M(S D)$ & $47.64(17,68)$ & $44.13(17.20)$ & $49.88(17.82)$ & $0.009^{5}$ & $39.96(14.58)$ & $51.44(17.68)$ & $0.009^{8}$ \\
\hline Marital status, \% & & & & $0.318^{6}$ & & & $0.009^{6}$ \\
\hline Never married & 29.3 & 32.0 & 23.0 & & 48.1 & 27.8 & \\
\hline Married/cohabiting & 49.8 & 49.5 & 51.4 & & 42.9 & 52.8 & \\
\hline Separated & 1.9 & 1.5 & 1.8 & & 1.5 & 2.3 & \\
\hline Divorced & 11.0 & 11.0 & 11.9 & & 7.5 & 11.6 & \\
\hline Widowed & 7.5 & 6.0 & 11.9 & & 0 & 5.6 & \\
\hline \multicolumn{8}{|l|}{$\begin{array}{l}\text { Headache-related } \\
\text { variables }\end{array}$} \\
\hline $\begin{array}{l}\text { Headache frequency, } \\
\%\end{array}$ & & & & $0.765^{6}$ & & & $1.000^{6}$ \\
\hline$<4$ days a month & 79.5 & 80.0 & 74.8 & & 85.0 & 84.2 & \\
\hline 4-14 days a month & 15.8 & 14.5 & 18.9 & & 11.3 & 14.0 & \\
\hline$>14$ days a month & 4.7 & 5.5 & 6.3 & & 3.3 & 1.8 & \\
\hline HIT-6 ${ }^{1}, \%$ & & & & $0.392^{6}$ & & & $1.000^{6}$ \\
\hline No or little impact & 41.8 & 41.6 & 32.2 & & 53.5 & 50.7 & \\
\hline Moderate impact & 25.2 & 26.4 & 24.7 & & 23.3 & 26.1 & \\
\hline Substantial impact & 12.2 & 12.2 & 15.4 & & 10.1 & 7.6 & \\
\hline Severe impact & 20.9 & 19.8 & 26.7 & & 13.2 & 15.6 & \\
\hline $\begin{array}{l}\text { Headache duration } \\
\text { (in years), } M(S D)\end{array}$ & $12.42(11.72)$ & $12.96(12.02)$ & $12.82(11.78)$ & $0.765^{5}$ & $10.19(10.51)$ & $12.52(11.91)$ & $1.000^{5}$ \\
\hline Migraine (yes), \% & 18.6 & 19.9 & 22.9 & $0.765^{7}$ & 13.5 & 12.7 & $1.000^{7}$ \\
\hline \multicolumn{8}{|l|}{ Other health variables } \\
\hline Obesity $^{2}$ (yes), \% & 19.5 & 16.2 & 23.1 & $0.318^{7}$ & 8.5 & 22.9 & $0.009^{7}$ \\
\hline Depression $^{3}$ (yes), \% & 11.8 & 8.6 & 16.4 & $0.077^{7}$ & 10.6 & 7.3 & $1.000^{7}$ \\
\hline
\end{tabular}

Bold $p$-values indicate significant associations

Weighted random sample; ${ }^{1}$ HIT-6, Headache Impact Test, ${ }^{2}$ obesity based on the body mass index $(\mathrm{BMI})\left(\mathrm{kg} / \mathrm{m}^{2}\right)$, obesity is defined as a BMI > 30; ${ }^{3} \mathrm{PHQ}-4$, Patient Health Questionnaire, depressive subscale encompasses two items and has sum scores ranging from 0 to 6 , scores $\geq 3$ indicate depression; ${ }^{4}$ Adjusted $p$ values based on the Holm-Bonferroni method; ${ }^{5}$ Welch's $t$ test; ${ }^{6}$ Pearson's $\chi^{2}$ test; ${ }^{7}$ Fisher's exact test; ${ }^{8} t$ test 

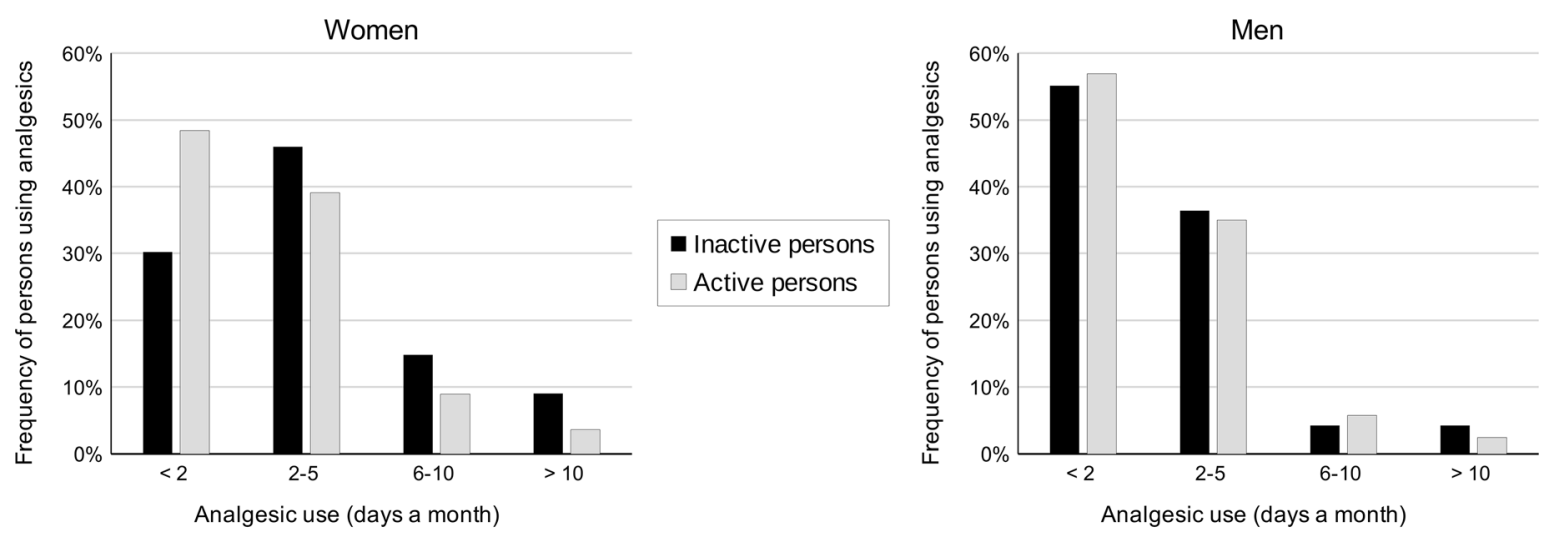

Fig. 1 Frequency (in \%) of analgesic use (days a month) depending on physical activity for women and men

Further significant predictors were age, headache frequency, headache impact, and depression. All of these were positively associated with the frequency of analgesic use.

Overall, the model accounted for approximately $35 \%$ of the variance in frequency of analgesic use (Nagelkerke's pseudo- $R^{2}$ ). For men, the results of the ordered logit models did not suggest any association between physical inactivity and frequency of analgesic use, $O R=$ $1.17,95 \%$ CI $[0.76,1.79]$, Wald $\chi^{2}(1)=0.51$, $p=0.475$ (Model 1). Associations also remained the same when sociodemographic, headacherelated variables and health variables were considered in Models 2, 3, and 4 (Table 3).

Predictor variables for frequency of analgesic use were marital status, headache frequency, headache impact, headache duration, and depression (Model 4). Compared to never-married men, married cohabiting men were more likely to have an increase in frequency of analgesic use. Headache frequency, headache impact, headache duration, and depression were positively associated with the frequency of analgesic use. Overall the model accounted for approximately $40 \%$ of the variance in the outcome (Nagelkerke's pseudo- $R^{2}$ ).

\section{DISCUSSION}

The present study investigates a mostly neglected aspect in the relationship between physical activity and headache, namely, whether physical activity is associated with less analgesic use.
This has not yet been examined in other studies. Factors associated with analgesic consumption in headache sufferers remain poorly understood.

Two main findings were revealed. First, frequent headache, severe impact of headache on daily life, and depressive symptoms were associated with higher analgesic use in both men and women. Second, the association between physical inactivity and analgesic consumption differed between the sexes. In women, we found a statistically significant association between physical inactivity and higher analgesic consumption, which remained significant even after controlling for age, marital status, headache frequency, headache impact, headache duration, migraine, obesity, and depression. In men, there was no difference in analgesic use between physically active and inactive persons.

Regarding the association between headache frequency respectively headache impact and analgesic use, the first main finding had been expected and is in line with data from the longitudinal and cross-sectional Migraine in America Symptoms and Treatment (MAST) Study, a survey of US adults 18 years or older with migraine [23]. Furthermore, we found a positive association between depression and analgesic use, independent of sociodemographic and headache-related factors. This relationship between depression and analgesic use has also been demonstrated by Hena \& Leung [24]. In their cross-sectional study with adolescents, the authors reported a positive 


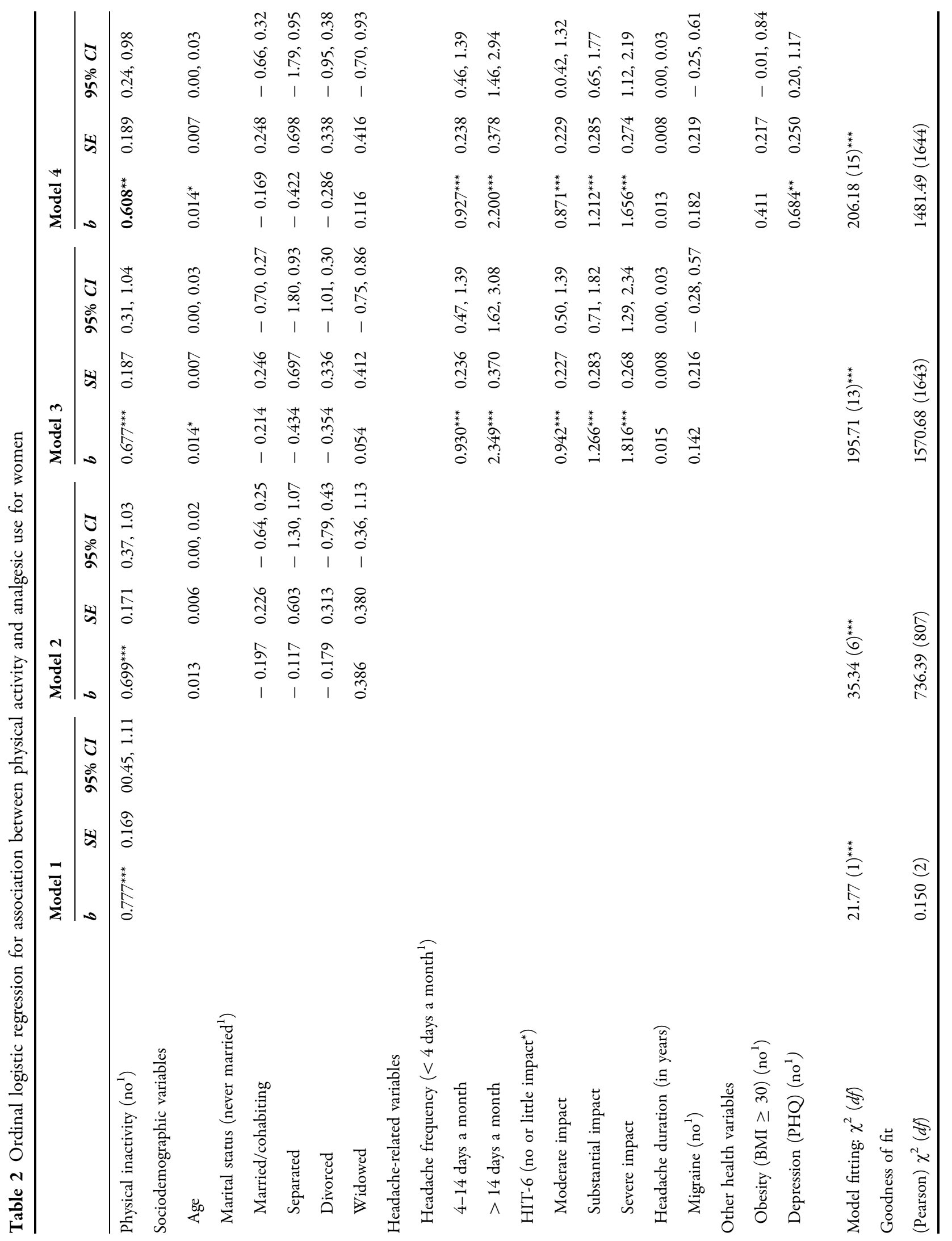




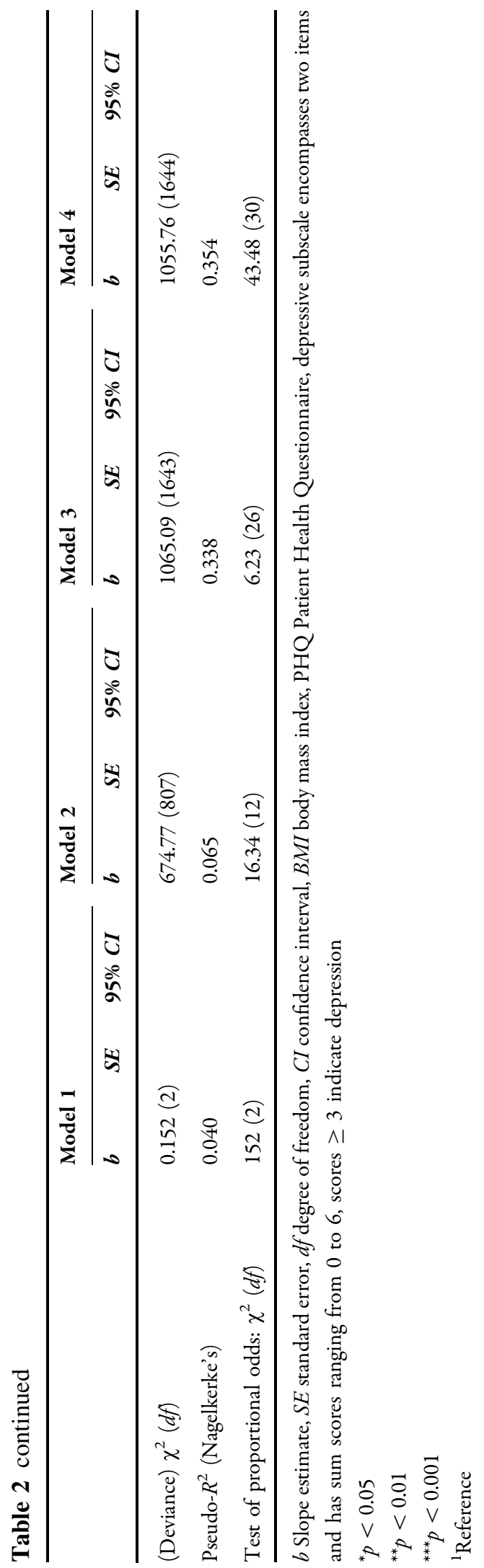

association between depression and analgesic consumption after controlling for headache and stomachaches. Wasan \& Davar [25] found evidence based on their double-blind, placebocontrolled, random crossover designed study that psychological symptom severity (composite score on depression, anxiety, and neuroticism) was associated with diminished opioid analgesia in patients with discogenic low back pain. The causal relationship between depression and analgesic use is unclear, but some potential explanations are discussed in the literature. Depression may lower the pain threshold and decrease the response to analgesics [26]. Furthermore, people with depression may use analgesics to treat their emotional pain [27].

Additionally, we found a significant association between physical inactivity and higher analgesic consumption in women. The association between physical inactivity and higher analgesic use matches the results of previous population-based studies. Dale, Borchgrevink [28] found in their Norwegian Nord-Trøndelag Health Study (HUNT) with participants 20 years or older that participants with little physical activity had 1.5-4 times greater risk of daily use of over-the-counter (OTC) analgesics compared to physically active subjects. This is in line with the results of a German study with adults aged 18-79 years [29]. Participants performing more than $4 \mathrm{~h}$ of physical exercise per week consumed significantly less analgesics (OTC and prescribed analgesics). Intervention studies found positive effects of exercise on analgesic use for patients with knee and hip osteoarthritis [30] and nonspecific acute low back pain [31]. To our knowledge, this effect has not yet been studied for patients with headache.

We assume that in our study the relationship between physical activity and analgesic use in women can essentially be explained by the pain-reducing effect of physical activity. This is supported by several intervention studies as mentioned above [30, 31]. In headache research, pain-reducing effects of physical activity have been demonstrated in patients with migraine and TTH, and different pathophysiological mechanisms have been discussed [2, 32-34]. 


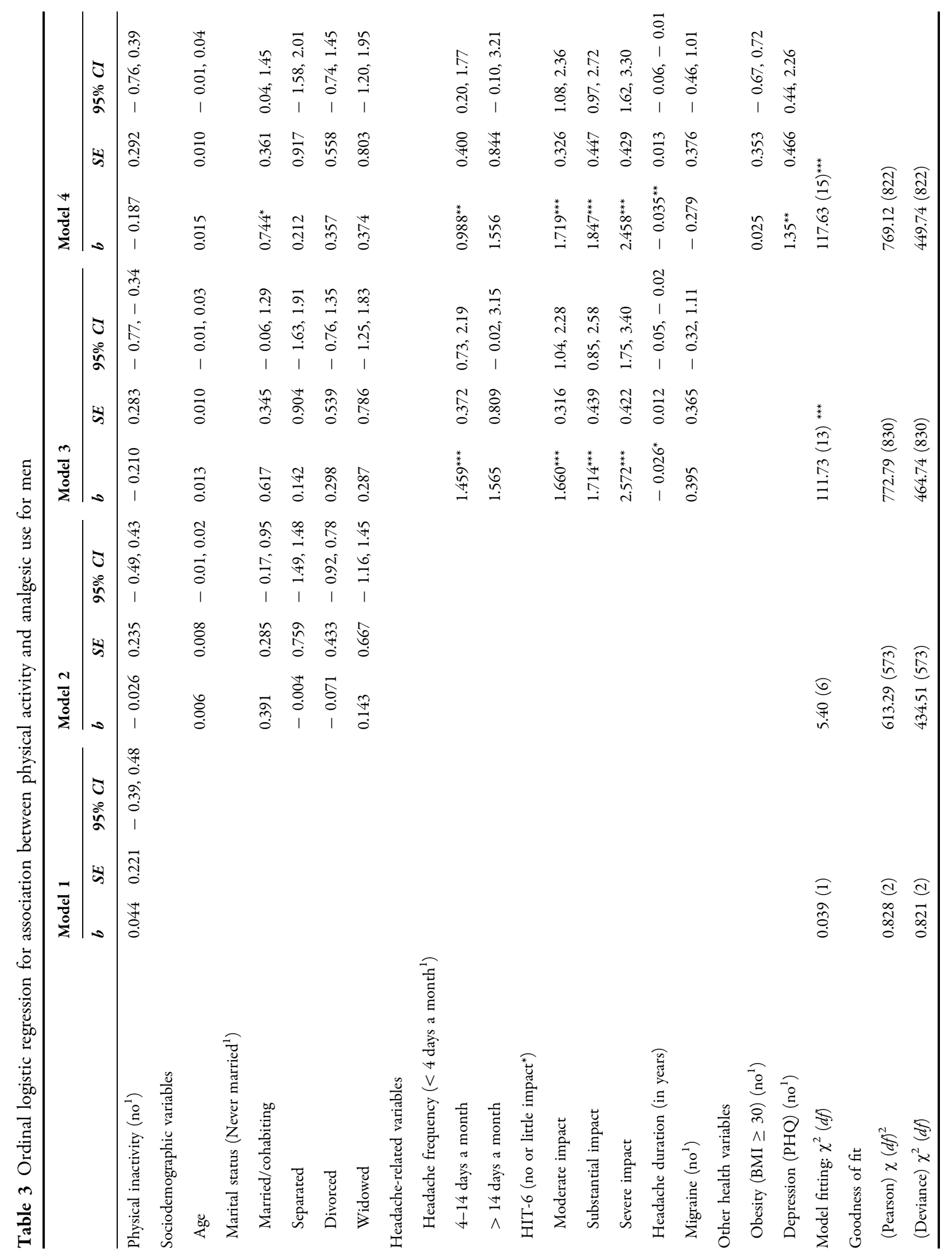




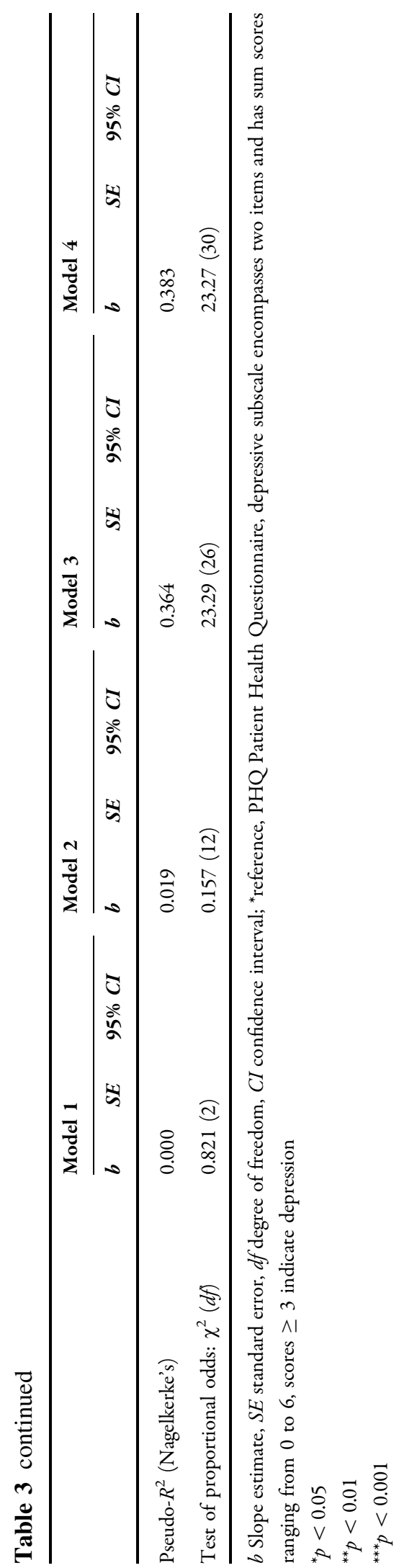

Our main finding is the association between physical activity and analgesics present only in women. To our knowledge, this finding has not been reported before.

In contrast to general population-based data that revealed higher proportions of physical activity in men than women, we found no sex difference in physical activity among headache sufferers $[35,36]$. While the proportion of physically active women with headache corresponds to that of women in the general population, men with headache are less physically active than men in a general population. Despite headache, women remain physically active. One reason could be that women with headache are more likely than men with headache to use physical activity as non-pharmacological prophylaxis. This interpretation is supported by the results of previous studies that have shown sex-specific motives for physical activity. There is some evidence that women tend especially to engage in sports when they feel responsible and capable for their own health. In contrast, no higher prevalence for physical activity was found among men who took responsibility for their own health [37-39]. Men were more motivated than women by competition and challenge $[40,41]$.

Furthermore, in women, the association between physical activity and analgesic use remained significant after controlling for headache-related variables, such as headache frequency and headache impact. Dale and Borchgrevink [28] found a similar result. The authors reported an association between physical activity duration and reduced daily use of paracetamol and/or NSAIDs both in participants with and without chronic pain that is maintained even after controlling for pain intensity. One possible explanation is to utilize a health lifestyle approach [42]. According to this approach, health behaviors occur as bundles of behaviors shaped by group-based identities, norms, and understanding of health [42, 43]. In their recent study, Mollborn, Lawrence [43] identified different health lifestyles based on data regarding physical activity, substance use (tobacco, marijuana, other drugs), alcohol use, diet, health care (medical check-up, visiting a dentist), sleep, and sexual risk. Given these 
results, we assume that both physical activity and low analgesic intake could be indicators of the same health lifestyle. This assumption is suggested by studies showing a healthier lifestyle among complementary and alternative medicine (CAM) users compared to non-CAM users [44-46]. Speculations about the impact of a healthy lifestyle pertain valetudinarian frames of mind, too. With regard to the latter people may be more inclined to take analgesics when they seek to avoid exercise. To separate between influences of healthy lifestyle versus valetudinarian frames of mind remains an open question for further research, since tailored interventions have to separate between these two mechanisms of analgesic use. It is possible that these gender differences in physical activity in headache are amplified by the specific mechanisms of pain processing in men and women. Evidence shows that men are less sensitive to pain and more tolerant to pain than women [47]. Our results suggest the prophylactic potential for exercise to positively influence patients' headache. Clinicians should especially educate women with high analgesic use about the solid evidence of physical activity for prophylactic treatment of headache and, in addition, about the risk of $\mathrm{MOH}$. As reduced physical activity and increased analgesic use may be fully integrated into the patients' health lifestyles, it can be assumed that these activities are often highly resistant to change and strongly influenced by social group memberships [43]. Therefore, education and counselling should be embedded in a resource-oriented approach and practitioners should especially consider the association found in women.

The present study has several strengths. It is the first to investigate the association between physical activity and analgesic intake in participants with headache. It is clinically relevant to identify this association because both physical inactivity and medication use are known as risk factors for $\mathrm{MOH}[48,49]$. In the analysis, we used current data on headache and headache treatment from a representative German sample, which covered a wide age range including older and elderly participants with headache. The definition of physical activity (on average at least 2-3 times a week for $30 \mathrm{~min}$ or longer) roughly corresponds to the current WHO recommendations (75-150 min per week) [50]. This ensures good comparability of our results with future research.

Our study has some limitations. In our sample, men took fewer analgesics than women, which corresponds with other studies [51, 52]. Additionally, men reported lower headache frequency and headache-related impairment than women. Thus, the reduced headache burden and subsequent lower analgesic use in men could have prevented the detection of a significant association with physical activity. Furthermore, only self-reported data regarding headache, physical activity and analgesic use were analyzed, which might be influenced by report bias. In our study, there was no criterion to exclude secondary headache. Therefore, we must assume that those participants were also included in the analyses. According to studies, the proportion of individuals with secondary headache among all participants with headache is $8-10 \%$ [53]. While we cannot rule out an effect of secondary headache on our results, but we estimate it to be small. No information about forms (aerobic vs. resistance training) was collected. We assume the proportion of the variance explained by this difference to be small however, as sex differences for both kinds of sport appear to be small in Germany [54]. An addition, no information on types and doses of analgesics was given. Furthermore, analgesic use and physical activity may also be influenced by the occurrence of comorbid disorders such as arthrosis or chronic lumbar pain. Unfortunately, no data were available to investigate this hypothesis further. We used cross-sectional data, which prevents drawing conclusions about the causality of the identified associations. On the one hand, it could be that taking more analgesics, which indicates a higher pain burden, reduces the likelihood of being physically active. In addition, migraine attacks get worse on physical activity, a reason why patients with migraine seek rest during attacks or stop their physical activities. Some patients with migraine report their attacks being triggered by physical activity. On the other hand, it could be that being physically active has the desired prophylactic 
effect as stated in the guidelines. Physical activity may also offer another way to cope with the burden of headache.

\section{CONCLUSIONS}

To conclude, our study shows meaningful associations of physical activity and reduced analgesic use in women, further supporting the important role of exercising regularly in headache disorders. Especially in the prevention of $\mathrm{MOH}$, this could be of therapeutic relevance. As the relationships are complex and embedded in a multifactorial set of conditions, future experimental research and clinical trials are needed to elucidate these aspects further.

\section{ACKNOWLEDGEMENTS}

We would like to thank all participants of the study.

Funding. This is a research project of the German Migraine and Headache Society (DMKG). The journal's Rapid Service Fee was funded by the German Migraine and Headache Society (DMKG).

Authorship. All named authors meet the International Committee of Medical Journal Editors (ICMJE) criteria for authorship for this article, take responsibility for the integrity of the work as a whole, and have given their approval for this version to be published.

Author Contributions. Charly Gaul, Tim P. Jürgens, Peter Kropp, Andreas Straube, Elmar Brähler, and Stefanie Förderreuther contributed conception of the study. Britta Müller performed the statistical analysis, Britta Müller, Thomas Dresler, and Olaf Reis wrote the first draft of the manuscript. Britta Müller, Charly Gaul, Änne Glass, Olaf Reis, Tim P. Jürgens, Peter Kropp, Ruth Ruscheweyh, Andreas Straube, Elmar Brähler, Stefanie Förderreuther, and Thomas Dresler reviewed and edited the manuscript. All authors approved the final version of the manuscript.
Disclosures. Charly Gaul has received honoraria for consulting and lectures within the past three years from Allergan Pharma, Lilly, Novartis Pharma, Hormosan Pharma, Grünenthal, Sanofi-Aventis, Weber \& Weber, Lundbeck, Perfood, and TEVA. His research is supported by a grant of the German Research Foundation (DFG). He does not hold any stocks of pharmaceutical companies. He is honorary secretary of the German Migraine and Headache Society. Tim P. Jürgens has served on advisory boards and/or has received honoraria for lectures from Allergan, Grünenthal, Hormosan, Lilly, Lundbeck, Novartis, Sanofi, ad TEVA. He has received royalties from Elsevier and Springer. His research is supported by Grants from the Innovationsfonds/ Gemeinsamer Bundesausschuss and the European Union (EFRE). He does not hold any stocks of pharmaceutical companies and is currently president of the German Migraine and Headache Society. Peter Kropp has received funding from Takeda, travel- and lecture - fees from Novartis, Lilly, and Teva. Ruth Ruscheweyh has received travel grants and/or honoraria from Allergan/ AbbVie, Hormosan, Lilly, Novartis and Teva. Andreas Straube has received honoraria for lectures and consultations within the past three years from Allergan, Allergosan, Bayer, Lilly, Novartis, Teva. Stefanie Förderreuther has received honoraria for lectures and consultations within the past three years from Allergan, Hormosan, Lilly, Novartis, Sanofi, TEVA. Thomas Dresler has received honoraria for consulting and lectures within the past three years from Hormosan Pharma, Novartis Pharma, and TEVA. Elmar Brähler, Britta Müller, Olaf Reis, and Änne Glas declare that they have nothing to disclose.

Compliance with Ethics Guidelines. The Ethics Committee of the Faculty of Medicine, University of Leipzig reviewed and approved the study (297/16-ek). All participants gave their written informed consent.

Data Availability. The datasets generated during and/or analyzed during the current study are available from the corresponding author on reasonable request. 
Open Access. This article is licensed under a Creative Commons Attribution-NonCommercial 4.0 International License, which permits any non-commercial use, sharing, adaptation, distribution and reproduction in any medium or format, as long as you give appropriate credit to the original author(s) and the source, provide a link to the Creative Commons licence, and indicate if changes were made. The images or other third party material in this article are included in the article's Creative Commons licence, unless indicated otherwise in a credit line to the material. If material is not included in the article's Creative Commons licence and your intended use is not permitted by statutory regulation or exceeds the permitted use, you will need to obtain permission directly from the copyright holder. To view a copy of this licence, visit http://creativecommons.org/licenses/by$\mathrm{nc} / 4.0 /$.

\section{REFERENCES}

1. Lemmens J, De Pauw J, Van Soom T, Michiels S, Versijpt J, Van Breda E, et al. The effect of aerobic exercise on the number of migraine days, duration and pain intensity in migraine: a systematic literature review and meta-analysis. J Headache Pain. 2019;20(1):16.

2. Machado-Oliveira L, da Gauto YOS, de Neto FJS, da Silva MG, Germano-Soares AH, Diniz PRB. Effects of different exercise intensities on headache: a systematic review. Am J Phys Med Rehabil. 2020;99(5): 390-6.

3. Pellegrino ABW, Davis-Martin RE, Houle TT, Turner DP, Smitherman TA. Perceived triggers of primary headache disorders: a meta-analysis. Cephalalgia. 2018;38(6):1188-98.

4. Levin M. The international classification of headache disorders, (ICHD III)-changes and challenges. Headache. 2013;53(8):1383-95.

5. Hindiyeh NA, Krusz JC, Cowan RP. Does exercise make migraines worse and tension type headaches better? Curr Pain Headache Rep. 2013;17(12):380.

6. Bendtsen L, Evers S, Linde M, Mitsikostas D, Sandrini G, Schoenen J. EFNS guideline on the treatment of tension-type headache-report of an EFNS task force. Eur J Neurol. 2010;17(11):1318-25.
7. Diener H-C, Holle-Lee D, Nägel S, Dresler T, Gaul C, Göbel $\mathrm{H}$, et al. Treatment of migraine attacks and prevention of migraine: guidelines by the German Migraine and Headache Society and the German Society of Neurology. Clin Transl Neurol. 2019;3(1): $1-40$.

8. Straube A, Förderreuther S, Eren OE. Tension type headaches: Quo vadis? Schmerz. 2020;34(6): 464-75. https://doi.org/10.1007/s00482-02000495-5.

9. Krøll LS, Hammarlund CS, Linde M, Gard G, Jensen RH. The effects of aerobic exercise for persons with migraine and co-existing tension-type headache and neck pain. A randomized, controlled, clinical trial. Cephalalgia. 2018;38(12):1805-16.

10. Santiago MDS, Carvalho DdS, Gabbai AA, Pinto MMP, Moutran ARC, Villa TR. Amitriptyline and aerobic exercise or amitriptyline alone in the treatment of chronic migraine: a randomized comparative study. Arq Neuropsiquiatr. 2014;72(11):851-5.

11. Hagen K, Linde M, Steiner TJ, Stovner LJ, Zwart J-A. Risk factors for medication-overuse headache: an 11-year follow-up study. The Nord-Trøndelag health studies. Pain. 2012;153(1):56-61.

12. Viana M, Bottiroli S, Sances G, Ghiotto N, Allena M, Guaschino E, et al. Factors associated to chronic migraine with medication overuse: a cross-sectional study. Cephalalgia. 2018;38(14):2045-57.

13. Niclós G, Olivar T, Rodilla V. Factors associated with self-medication in Spain: a cross-sectional study in different age groups. Int J Pharm Pract. 2018;26(3):258-66.

14. Porter JK, Di Tanna GL, Lipton RB, Sapra S, Villa G. Costs of acute headache medication use and productivity losses among patients with migraine: insights from three randomized controlled trials. Pharmacoecon Open. 2019;3(3):411-7.

15. Kosinski M, Bayliss M, Bjorner J, Ware J, Garber W, Batenhorst A, et al. A six-item short-form survey for measuring headache impact: the HIT- $6^{\mathrm{TM}}$. Qual Life Res. 2003;12(8):963-74.

16. Organization WH. Overweight and obesity. WHO; 2020.

17. Kroenke K, Spitzer RL, Williams JB, Löwe B. An ultra-brief screening scale for anxiety and depression: the PHQ-4. Psychosomatics. 2009;50(6): 613-21.

18. Löwe B, Wahl I, Rose M, Spitzer C, Glaesmer H, Wingenfeld $\mathrm{K}$, et al. A 4-item measure of depression and anxiety: validation and standardization of the 
Patient Health Questionnaire-4 (PHQ-4) in the general population. J Affect Disord. 2010;122(1-2): 86-95.

19. Holm S. A simple sequentially rejective multiple test procedure. Scand J Stat. 1979;6(2):65-70.

20. Schochet PZ. Technical methods report: guidelines for multiple testing in impact evaluations. NCEE 2008-4018. National Center for Education Evaluation and Regional Assistance. 2008.

21. Agresti A, Kateri M. Categorical data analysis. Springer; 2011.

22. Müller B, Dresler T, Gaul C, Glass Ä, Jürgens TP, Kropp $\mathrm{P}$, et al. More attacks and analgesic use in old age: self-reported headache across the lifespan in a German sample. Front Neurol. 2019;10:1000.

23. Schwedt TJ, Alam A, Reed ML, Fanning KM, Munjal $S$, Buse DC, et al. Factors associated with acute medication overuse in people with migraine: results from the 2017 migraine in America symptoms and treatment (MAST) study. J Headache Pain. 2018;19(1):1-9.

24. Hena M, Leung C, Clausson EK, Garmy P. Association of depressive symptoms with consumption of analgesics among adolescents. J Pediatr Nurs. 2019;45:e19-23.

25. Wasan AD, Davar G, Jamison R. The association between negative affect and opioid analgesia in patients with discogenic low back pain. Pain. 2005;117(3):450-61.

26. Thompson T, Correll CU, Gallop K, Vancampfort D, Stubbs B. Is pain perception altered in people with depression? A systematic review and meta-analysis of experimental pain research. J Pain. 2016;17(12): 1257-72.

27. Lehrer S. Nonsteroidal anti-inflammatory drugs (NSAIDs) reduce suicidal ideation and depression. Discov Med. 2019;28(154):205-12.

28. Dale O, Borchgrevink PC, Fredheim OMS, Mahic M, Romundstad P, Skurtveit S. Prevalence of use of non-prescription analgesics in the Norwegian HUNT3 population: impact of gender, age, exercise and prescription of opioids. BMC Public Health. 2015;15(1):1-9.

29. Sarganas G, Buttery AK, Zhuang W, Wolf I-K, Grams $\mathrm{D}$, Rosario AS, et al. Prevalence, trends, patterns and associations of analgesic use in Germany. BMC Pharmacol Toxicol. 2015;16(1):1-13.

30. Thorlund JB, Roos EM, Goro P, Ljungcrantz EG, Grønne DT, Skou ST. Patients use fewer analgesics following supervised exercise therapy and patient education: an observational study of 16,499 patients with knee or hip osteoarthritis. Br J Sports Med. 2021;55(12):670-5.

31. Lingner H, Blase L, Großhennig A, Schmiemann G. Manual therapy applied by general practitioners for nonspecific low back pain: results of the ManRück pilot-study. Chiropract Manual Ther. 2018;26(1): $1-14$.

32. Bigal ME, Lipton RB. The epidemiology, burden, and comorbidities of migraine. Neurol Clin. 2009;27(2):321-34.

33. Amin FM, Aristeidou S, Baraldi C, Czapinska-Ciepiela EK, Ariadni DD, Di Lenola D, et al. The association between migraine and physical exercise. J Headache Pain. 2018;19(1):1-9.

34. Madsen BK, Søgaard K, Andersen LL, Tornøe B, Jensen RH. Efficacy of strength training on tensiontype headache: a randomised controlled study. Cephalalgia. 2018;38(6):1071-80.

35. Cockerham WC. Health lifestyles and the search for a concept of a gender-specific habitus. Soc Theory Health. 2018;16(2):142-55.

36. Guthold R, Stevens GA, Riley LM, Bull FC. Global trends in insufficient physical activity among adolescents: a pooled analysis of 298 population-based surveys with 1.6 million participants. Lancet Child Adolesc Health. 2020;4(1):23-35.

37. Weiss W. Zweiter Berner Gesundheits bericht. Bern: Gesundheits-und Fürsorgedirektion des Kantons Bern; 2000.

38. Martin B, Lamprecht $M$, Calmonte R, Raeber P, Marti B. Körperliche Aktivität in der Schweizer Bevölkerung: Niveau und Zusammenhänge mit der Gesundheit. Gemeinsame wissenschaftliche Stellungnahme von Bundesamt für Sport (BASPO), Bundesamt für Gesundheit (BAG), Bundesamt für Statistik (BFS) und Netzwerk Gesundheit und Bewegung Schweiz. Schweiz Z Sportmed Sporttraumatol. 2000;48(2):87-8.

39. Lamprecht M, Stamm H. Age and gender patterns of sport involvement among the Swiss labor force. Sociol Sport J. 1996;13(3):274-87.

40. Egli T, Bland HW, Melton BF, Czech DR. Influence of age, sex, and race on college students' exercise motivation of physical activity. J Am Coll Health. 2011;59(5):399-406.

41. Molanorouzi K, Khoo S, Morris T. Motives for adult participation in physical activity: type of activity, age, and gender. BMC Public Health. 2015;15(1): $1-12$. 
42. Cockerham WC. Health lifestyle theory and the convergence of agency and structure. J Health Soc Behav. 2005;46(1):51-67.

43. Mollborn S, Lawrence EM, Hummer RA. A gender framework for understanding health lifestyles. Soc Sci Med. 2020;265:113182.

44. van der Werf ET, Busch M, Jong MC, Hoenders H. Lifestyle changes during the first wave of the COVID-19 pandemic: a cross-sectional survey in the Netherlands. BMC Public Health. 2021;21(1):1-11.

45. Davis MA, West AN, Weeks WB, Sirovich BE. Health behaviors and utilization among users of complementary and alternative medicine for treatment versus health promotion. Health Serv Res. 2011;46(5):1402-16.

46. Nahin RL, Dahlhamer JM, Taylor BL, Barnes PM, Stussman BJ, Simile CM, et al. Health behaviors and risk factors in those who use complementary and alternative medicine. BMC Public Health. 2007;7(1):1-9.

47. Mogil JS. Qualitative sex differences in pain processing: emerging evidence of a biased literature. Nat Rev Neurosci. 2020;21(7):353-65.

48. Westergaard ML, Glümer C, Hansen EH, Jensen RH. Medication overuse, healthy lifestyle behaviour and stress in chronic headache: results from a population-based representative survey. Cephalalgia. 2016;36(1):15-28.

49. Vandenbussche N, Laterza D, Lisicki M, Lloyd J, Lupi C, Tischler $\mathrm{H}$, et al. Medication-overuse headache: a widely recognized entity amidst ongoing debate. J Headache Pain. 2018;19(1):1-14.

50. Bull FC, Al-Ansari SS, Biddle S, Borodulin K, Buman MP, Cardon G, et al. World Health Organization 2020 guidelines on physical activity and sedentary behaviour. Br J Sports Med. 2020;54(24):1451-62.

51. Barrenberg E, Knopf H, Garbe E. Over-the-counter (OTC) drug consumption among adults living in Germany: results from the German Health Interview and Examination Survey for Adults 2008-2011 (DEGS1). Pharmacy. 2018;6(2):52.

52. Beitz R, Dören M, Knopf H, Melchert H-U. Selbstmedikation mit Over-the-Counter-(OTC-) Präparaten in Deutschland. BundesgesundheitsblattGesundheitsforschung-Gesundheitsschutz. 2004;47(11):1043-50.

53. Dodick DW. Pearls: headache. Semin Neurol. 2010;30(1):74-81.

54. Finger JD, Mensink G, Lange C, Manz K. Healthenhancing physical activity during leisure time among adults in Germany. J Health Monit. 2017;2(2):37-44. https://doi.org/10.17886/RKIGBE-2017-027. 